\begin{tabular}{|c|l|}
\hline Title & Price setting and competition with search frictions \\
\hline Author(s) & Kudoh, Noritaka \\
\hline Citation & Discussion Paper, Series A, 203, 1-29 \\
\hline Issue Date & 2009-02 \\
\hline Doc URL & http://hdl.handle.net/2115/35514 \\
\hline Type & bulletin (article) \\
\hline File Information & DPA 203.pdf \\
\hline
\end{tabular}

Instructions for use 
Discussion Paper, Series A, No. 2009-203

\title{
Price Setting and Competition with Search Frictions
}

\author{
Noritaka Kudoh
}

February, 2009

Graduate School of Economics \& Business Administration Hokkaido University

Kita 9 Nishi 7, Kita-Ku, Sapporo 060-0809, JAPAN 


\title{
Price Setting and Competition with Search Frictions*
}

\author{
Noritaka Kudoh ${ }^{\dagger}$ \\ Hokkaido University
}

\begin{abstract}
This paper investigates price determination in a decentralized economy in which buyers' valuations are stochastic and unobservable. In such a market, each buyer's reservation utility depends both on the prevailing price and on the price he actually encounters. The buyer's willingness to trade is shown to be decreasing in the price, and this creates the trade-off for the sellers' price setting. Even though the sellers have incentives to manipulate the buyer's willingness to trade, the economy is not fully competitive; it does not converge to the Walrasian outcome as search frictions disappear. The model is used to study various market structures to explore the nature of market power in search equilibrium. It is shown that price dispersion arises as a result of search frictions and oligopolistic price setting.
\end{abstract}

JEL classification: C78, D40

Keywords: random search, price setting, competition, oligopoly.

${ }^{*}$ I wish to thank Takeshi Yamazaki, Masaru Sasaki, Hiroyuki Adachi, Ryoichi Imai, Shingo Ishiguro, Hideo Konishi, and the participants of seminars at Hokkaido University, Kansai University, Osaka University (ISER) and Otaru University of Commerce, and the decentralization conferences at Hosei University and Kinki University for helpful comments.

${ }^{\dagger}$ Department of Economics, Kita 9 Nishi 7, Kita-ku, Sapporo 060-0809, JAPAN; Email: kudoh@econ.hokudai.ac.jp 


\section{Introduction}

In textbook microeconomics, buyers behave as price takers. They submit their entire demand schedules to the Walrasian auctioneer, who aggregates them to produce a single downward-sloping demand schedule. If firms have some market power, then the demand schedule defines the tradeoff they face between price and quantity. In other words, sellers can (potentially) manipulate the buyers' willingness to trade through their prices. In many of the search-matching models, on the other hand, the terms of trade are determined by bilateral bargaining (Rubinstein and Wolinsky, 1985; Mortensen and Wright, 2002) or by price posting (Acemoglu and Shimer, 1999; Curtis and Wright, 2004), and the demand manipulation has not been considered.

This paper investigates the sellers' price setting in search equilibrium in which there is room for manipulating the buyers' willingness to trade through their prices. In a random search model, it is not trivial to obtain a trade-off that is similar to the textbook demand curve. ${ }^{1}$ As the analysis in Wolinsky (1986) suggests, the buyers' willingness to trade is independent of the prices of commodities if the cost of search is a sampling cost rather than discounting of future utility. ${ }^{2}$ This paper develops a simple random search model in which discounting captures the degree of search frictions, and finds an exploitable trade-off between price and the acceptability of trade.

The structure of the model is related to other random search models such as Burdett and Wright (1998) and in particular Mortensen and Wright (2002). In terms of price setting, this paper is closely related to Albrecht and Jovanovic (1986) and in particular Masters (1999). The key features of this paper are: (i) it studies a random two-sided search model of the product market; (ii) the buyers' willingness to trade are stochastic and unobservable; (iii) each seller maximizes her value taking the buyer's reservation strategy as a constraint; and (iv) the basic model is extended to study other market structures such as monopoly and oligopoly.

Throughout this paper, search is two-sided and random. Although the recent development of

\footnotetext{
${ }^{1}$ There is a growing literature on directed search, where sellers post prices. The tradeoff in that literature is between price and the queue length. See Acemoglu and Shimer (1999) and Rogerson, Shimer, and Wright (2005) for expositions.

${ }^{2}$ This point is discussed in Section 4.2 in detail.
} 
directed search models is important and to some extent relevant to this paper, I focus on random search. Part of the reason for this is that the trade-off in the directed search model is between price and the queue length of buyers. In fact, the key issue in the directed search literature is to endogenize the matching frictions. The purpose of this paper is to explore how the sellers use the prices to manipulate the buyers' willingness to trade in the presence of search frictions.

In many models of decentralized trading, bilateral bargaining is used as the pricing institution. In particular, either the Nash solution or strategic bargaining (Rubinstein and Wolinsky, 1985) with observable match surplus is assumed in the literature. With observable valuations, the sellers would set their prices so that each buyer is just indifferent between accepting and rejecting a trade. This paper assumes that the buyers' valuations (or the maximum willingness to pay) are unobservable. With this realistic assumption, it is shown that each buyer's search strategy depends on the prices. In particular, a buyer's reservation utility depends on the prevailing price of the commodity and the price he actually faces. The reservation utility is shown to be decreasing in the price he faces.

This suggests that each seller believes that she can increase the probability that her customer, who will arrive at the seller's store at random, will purchase her commodity by cutting her price. That is, the seller faces an exploitable trade-off between price and acceptability. Technically, each seller maximizes her value of search, taking the buyer's reservation strategy as a constraint (Albrecht and Jovanovic, 1986; Masters, 1999). It is shown that there is a unique search equilibrium under this pricing scheme.

An important issue in the theory of decentralized trading is to explore the strategic foundation of general equilibrium (Rubinstein and Wolinsky, 1985; Gale, 1987; Wilson, 1987; Wolinsky, 1988; De Fraja and Sákovics, 2001; Mortensen and Wright, 2002). ${ }^{3}$ The present study also intends to contribute to this important literature. Following the literature, I study the properties of the basic model in the limit as search frictions disappear. Because of the constant measure of traders in the steady state (Gale, 1987), the decentralized economy does not converge to the Walrasian outcome, and the limit price depends on the relative measure of traders (Rubinstein and Wolinsky,

\footnotetext{
${ }^{3}$ For reviews, see Osborne and Rubinstein (1990) and Gale (2000).
} 
1985). It is important to emphasize that the price posting game is not responsible for the nonWalrasian outcome; the model with observable valuations and bilateral bargaining also leads to the non-Walrasian outcome. ${ }^{4}$

As applications of the basic model, this paper considers various forms of market structure. In the basic model, each seller ignores how her price will influence the buyers' willingness to trade through its impact on their values of search (or, the values of their options to wait). The failure to take into account the equilibrium relationship between price and the willingness to trade has a profound implication for the competitiveness of the economy. To see this, a monopoly version of the model is developed, in which all sellers form a single coalition called firm and the firm chooses the price. From a buyer's point of view, there are many sellers, but there are no competing sellers. It is shown that the firm sets a higher price. However, this is not the monopoly price in the sense of Diamond (1971); the buyers' values of search are positive because their valuations of the commodity are unobservable.

The Bertrand Paradox and the Diamond Paradox offer insightful angles to understanding the nature of competition. The former states that two firms are enough to generate the perfectly competitive outcome in an oligopoly model with price competition. The latter states that even with a large number of firms, the monopoly price will result as long as each buyer faces a small search cost. If there are two firms in a decentralized economy with search frictions, how competitive will the prices be? I characterize a duopoly version of the model and show that the prices are strategic substitutes, suggesting that there is no undercutting. In addition, price dispersion arises as a result of search frictions and oligopolistic price setting, which is new to the literature on price dispersion. Interestingly, the equilibrium is of the Cournot-type even though the firms compete by setting prices.

The organization of this paper is as follows. Section 2 presents the basic model and the equilibrium is studied in Section 3. Some of the results are related to the existing literature in Section 4. Section 5 extends the basic model to study the cases with monopoly and oligopoly. Section 6

\footnotetext{
${ }^{4}$ In a closely related environment, Mortensen and Wright (2002) showed that their economy generates the Walrasian outcome if potential entrants possess the options to stay out of the market.
} 
concludes. All proofs of the main results are presented in the Appendix.

\section{The Model}

\subsection{Environment}

Time is continuous, and the time horizon is infinite. There is a continuum of buyers and sellers, and each individual is atomless. Let $r$ denote the common discount rate. Search is undirected. In addition, there is no recall. After a trade, the buyer and seller leave the market, and their clones will replace them (Rubinstein and Wolinsky, 1985; De Fraja and Sákovics, 2001). This assumption maintains the stationarity of this economy. Thus, although the number of traders at each instant is finite, it accumulates over time without bound, leading to a non-Walrasian result (Gale, 1987). ${ }^{5}$

This paper follows Mortensen and Wright (2002) to adopt a general meeting technology. Let $B$ and $S$ denote the measure of buyers and sellers, respectively. The aggregate pairs made at each instant are determined by a constant-returns-to-scale function $m(B, S)$, which is increasing in both arguments. For a buyer, the arrival rate of a trade opportunity is given by $m / B \equiv \alpha_{b}$, and for a seller it is $m / S \equiv \alpha_{s}$. It is easy to verify that $\alpha_{b}$ is decreasing in the buyer-seller ratio $B / S \equiv q$ and $\alpha_{s}$ is increasing. With constant returns, it is easy to verity that $\alpha_{s}=q \cdot \alpha_{b}$. It is also assumed that $\lim _{q \rightarrow 0} \alpha_{s}=\lim _{q \rightarrow \infty} \alpha_{b}=0$ and $\lim _{q \rightarrow \infty} \alpha_{s}=\lim _{q \rightarrow 0} \alpha_{b}=\infty$.

Each seller produces a common consumption good. It is assumed that the cost of producing a unit of the commodity is $c>0$ and is common to all sellers. All goods are perishable and indivisible. I assume that production is instantaneous. A buyer's willingness to trade is stochastic. Upon meeting, a buyer finds the maximum willingness to pay for a commodity denoted by $v$. It is assumed that $v$ is a random draw from distribution $F(v)$, with support $[0, \bar{v}]$. It is assumed that $\bar{v}>c, 0<F^{\prime}(\bar{v})<\infty$, and $F^{\prime \prime}(\bar{v})<\infty$. A critical assumption is that each realization of $v$ is unobservable. However, sellers know the distribution $F$ as well as the structure of the economy.

\footnotetext{
${ }^{5}$ Mortensen and Wright (2002) followed Gale (1987) in assuming stochastic entry of traders and showed that their economy leads to the Walrasian outcome. De Fraja and Sákovics (2001) obtained the Walrasian outcome even with the clone assumption by introducing local (or instantaneous) market competition.
} 
A possible interpretation of this specification is that consumers" "mood" changes over time. The key, however, is that from a seller's viewpoint, the willingness to pay differs from one buyer to another. A related assumption is adopted by Wolinsky (1988) and Wang (1995). Alternatively, one could assume product differentiation (Wolinsky, 1986; Arbatskaya and Konishi, 2005). With this interpretation, $v$ measures how much a buyer likes a certain commodity, and the market structure should be interpreted as monopolistic competition. The two specifications are identical as long as each seller is treated symmetrically. ${ }^{6}$

The price of a commodity is denoted by $p$. It should be considered as a utility transfer rather than a monetary exchange. ${ }^{7}$ Thus, the instantaneous payoff to a buyer who accepts a trade at price $p$ is $v-p$. To simplify the analysis, I focus on a symmetric steady state equilibrium, in which all sellers follow the same strategy, so there is no price dispersion.

\subsection{Buyers}

Consider the choice of a typical buyer. Let $V_{b}(p)$ denote the value of search when the prevailing price is $p .^{8}$ Then, the Bellman equation for the buyer is

$$
r V_{b}(p)=\alpha_{b} \iint_{0}^{\bar{v}} \max \left\{v-p_{i}-V_{b}(p), 0\right\} d F(v) d G\left(p_{i}\right),
$$

where $G(\cdot)$ is the cumulative distribution function of the price, which is degenerate in equilibrium. Note that $v$ and $p_{i}$ are independent, since a seller, who cannot observe $v$, cannot condition her price on $v$. The reservation strategy requires that the buyer accepts a trade as soon as $v \geq R$ holds, where the reservation utility $R$ is given by

$$
R=p_{i}+V_{b}(p)
$$

for each $p_{i}$. Thus, the reservation utility is influenced by the prevailing price $p$ and the price posted by the seller in front of the buyer, $p_{i}$. In equilibrium, $p_{i}=p$. It is important to note that, for

\footnotetext{
${ }^{6}$ The reader who is familiar with Wolinsky (1986) will find it more appropriate to call each seller a monopolistically competitive firm. Since this paper redefines the term firm later, I shall call individual traders either buyers or sellers.

${ }^{7}$ See Curtis and Wright (2004) for a monetary exchange model with price setting.

${ }^{8}$ I follow Masters (1999) for this exposition. To be more precise, the value function depends on the entire price distribution $G(p)$.
} 
a given value of search, the reservation utility $R$ increases with $p_{i}$. This implies that a seller has an incentive to reduce her price to induce buyers to purchase the commodity from her. This is somewhat similar to textbook microeconomics, where a seller with some market power faces a trade-off between price and quantity sold, and the trade-off comes from the consumers' demand schedule. Although limited, each seller in this economy has some market power to the extent that buyers cannot walk away from a seller so easily, because of search frictions.

\subsection{Sellers}

Each seller is assumed to post a price when searching for a buyer. It is also assumed that sellers commit to their prices, and price commitment is costless. ${ }^{9}$ The value to a seller of posting $p_{i}$ when the prevailing price posted by all other sellers is $p$, is given by

$$
r V_{s}\left(p_{i}, p\right)=\alpha_{s}[1-F(R)]\left[p_{i}-c-V_{s}\left(p_{i}, p\right)\right]
$$

where $1-F(R)$ is the probability that a buyer is willing to trade at the posted price $p_{i}$. If a trade occurs, then the seller receives $p_{i}$, paying the production $\operatorname{cost} c$, and exits the market after the trade. The key feature of the model is that the arrival rate of a successful trade may be manipulated by each seller. To see this, the acceptability is written as $1-F(R)=1-F\left(p_{i}+V_{b}(p)\right)$. Substitute this into (3) to obtain

$$
r V_{s}\left(p_{i}, p\right)=\alpha_{s}\left[1-F\left(p_{i}+V_{b}(p)\right)\right]\left[p_{i}-c-V_{s}\left(p_{i}, p\right)\right]
$$

The seller faces a trade-off in an intuitive manner. If the price is high, her instantaneous utility is high given that the commodity is sold. On the other hand, a higher price reduces the chance that the commodity is sold. Facing this trade-off, the seller chooses $p$ to maximize her value of search, taking all other sellers' price strategies as given. This is where competition (potentially) comes in.

It is important to emphasize that although a seller can manipulate the acceptability of her commodity by posting a lower price, search is undirected. This contrasts with the recent directed

\footnotetext{
${ }^{9}$ Bester (1994) considered a model in which price commitment is costly, and showed that equilibrium with haggling is possible.
} 
search models, in which buyers can quote all prices at no cost and choose (and compete for) a seller (Acemoglu and Shimer, 1999). In this economy, buyers cannot either choose which sellers to visit or negotiate the terms of trade; they can only choose whether to accept a trade at the posted price or to walk away. In this sense, this economy is closer to the one considered by Diamond (1971). However, here, a seller cannot observe the buyer's willingness to trade, which effectively prevents the well-known Diamond Paradox from occurring.

Each seller's problem is: $\max _{p_{i}} V_{s}\left(p_{i}, p\right)$ subject to $R=p_{i}+V_{b}(p)$, taking $p$ and therefore $V_{b}$ as given. From the seller's perspective, cutting $p_{i}$ directly improves the buyer's willingness to trade. However, the seller fails to take into account how her choice will affect the equilibrium price and hence the buyer's value of search.

Proposition 1 Each seller posts

$$
p_{i}=c+\frac{[1-F(R)]+\left(\alpha_{s} / r\right)[1-F(R)]^{2}}{F^{\prime}(R)} \equiv P(R),
$$

where $P(R)$ is decreasing if

$$
-1<\frac{F^{\prime \prime}(R)}{F^{\prime}(R)^{2}}[1-F(R)]<2
$$

Proof. In the Appendix.

The first inequality of condition (6) holds if and only if the survival function $1-F$ is strictly log-concave. ${ }^{10}$ If the density function $F^{\prime}$ is log-concave, then the distribution function $F$ and the survival function 1-F are log-concave. See Burdett and Wright (1998) and Bagnoli and Bergstrom (2005) for details. Proposition 1 states that the price posting curve is downward sloping if the density function $F^{\prime}$ is log-concave. The second inequality in (6) is derived from the second-order condition for the maximization problem. In what follows, I will focus on the economy where (6) is satisfied.

In what follows, $P(R)$ is referred to as the price posting function. With log-concavity, the price posting function is decreasing, as shown in Figure 1. Note that a seller perceives $r / \alpha_{s}$ as the measure of market frictions. It is interesting to observe that as search frictions increase, the

\footnotetext{
${ }^{10}$ In general, a function $f$ is log-concave if and only if $f f^{\prime \prime}-\left(f^{\prime}\right)^{2} \leq 0$.
} 
price posting function shifts downward. This suggests that ceteris paribus, greater search frictions induce each seller to post a lower price.

\section{Equilibrium}

\subsection{Characterization}

In any symmetric steady-state equilibrium, all sellers set the same price: $p_{i}=p$. Thus, distribution $G(\cdot)$ is degenerate. Use the reservation strategy to rewrite the buyer's value (1) as

$$
r V_{b}(p)=\alpha_{b} \int_{R}^{\bar{v}}(v-R) d F(v)=\alpha_{b} \int_{R}^{\bar{v}}[1-F(v)] d v .
$$

Substitute (7) into (2) to obtain the equilibrium relationship between $p$ and $R$ as follows:

$$
p=R-\frac{\alpha_{b}}{r} \int_{R}^{\bar{v}}[1-F(v)] d v \equiv H(R) .
$$

Since $H^{\prime}(R)=1+\left(\alpha_{b} / r\right)[1-F(R)]$ and $H^{\prime \prime}(R)=-\left(\alpha_{b} / r\right) F^{\prime}(R)$ hold, it is easy to establish the following.

Lemma 2 (a) $H^{\prime}(R)>1$; (b) $H^{\prime \prime}(R)<0$; (c) $H(0)<0$ and $H(\bar{v})=\bar{v}$; and (d) $H^{\prime}(0)=1+\alpha_{b} / r$ and $H^{\prime}(\bar{v})=1$.

Figure 1 depicts the shape of function $H(R)$. This summarizes the equilibrium relationship between the price and the reservation utility. The steady-state equilibrium is completely characterized by a pair $(p, R)$ that satisfies (5) and (8), as depicted in the Figure.

Proposition 3 There exists a unique symmetric steady-state equilibrium.

Proof. In the Appendix.

The following reports some results on comparative statics.

Proposition 4 (a) The equilibrium willingness to trade increases with search frictions. (b) The equilibrium price increases with frictions if and only if

$$
\frac{\alpha_{b}}{\alpha_{s}} \frac{\left[r+\alpha_{s}[1-F(R)]\right][1+C(R)]+\alpha_{s}[1-F(R)]}{r+\alpha_{b}[1-F(R)]}>\frac{[1-F(R)]^{2}}{F^{\prime}(R) \int_{R}^{\bar{v}}[1-F(v)] d v},
$$


where $C(R)=F^{\prime \prime}(R) F^{\prime}(R)^{-2}[1-F(R)]$. (c) An increase in $B / S$ raises the price, and its impact on the willingness to trade is ambiguous.

Proof. In the Appendix.

In this economy, search frictions are captured by the discount rate $r$, the cost of waiting. As search frictions increase, buyers become more willing to trade now than later, which makes them more willing to purchase commodities at higher prices. This encourages the sellers to raise their prices. However, greater search frictions also imply that sellers too desire to trade as soon as possible (because waiting is costly). This effect will induce the sellers to cut prices. As a result, the effect of search frictions on prices is generally ambiguous.

An increase in $B / S$ raises the price because the sellers find it easier to meet buyers, so the sellers are more willing to wait for buyers with higher valuations. In addition, sellers know that buyers are more willing to trade for the same price level, so sellers can raise prices without losing much trade opportunity. However, the equilibrium willingness to trade may or may not increase because the increase in price has a negative impact on the willingness to trade.

\subsection{Walrasian Outcome}

A central question in the theory of decentralized trading is whether an economy with frictions converges to the Walrasian outcome as search frictions disappear (Rubinstein and Wolinsky, 1985; Gale, 1987; Wilson, 1987; Wolinsky, 1988; De Fraja and Sákovics, 2001; Mortensen and Wright, 2002). This section connects the model with the Walrasian outcome. Remember that the measure of traders in this economy is infinite because new traders enter the market to replace those who completed transactions. As pointed out by Gale $(1987,2000)$, defining the Walrasian outcome is a subtle matter. In this paper, I follow De Fraja and Sákovics (2001) and Mortensen and Wright (2002) to define the Walrasian outcome (in the steady-state sense) as follows.

Since each seller can produce at most one unit of the good, the quantity supplied is $S$ if the price exceeds $c$, and 0 otherwise. Since each buyer's maximum willingness to trade $v$ is drawn from $F(\cdot)$, the inverse demand function is $[1-F(v)] B$. Thus, the Walrasian price $p_{W}$ is the solution $v$ 
that satisfies $[1-F(v)] B=S$ for $v \geq c$, from which

$$
p_{W}=\left\{\begin{array}{cc}
F^{-1}\left[1-\frac{S}{B}\right] & \text { for } B \geq S \\
c & \text { for } B<S
\end{array}\right.
$$

where $F^{-1}$ is the inverse of $F$. Note that this definition of the Walrasian price requires market clearing at each moment, and the short side of the market gets all the trade surplus. Since this paper is concerned with competition among sellers, unless I state otherwise, I focus on the case with $B<S$ so that $p_{W}=c$.

Consider the decentralized economy. Does the equilibrium outcome get closer to the Walrasian outcome as search frictions disappear?

Proposition 5 In the limit as $r \rightarrow 0, R \rightarrow \bar{v}$ and

$$
p \rightarrow \frac{S c+2 B \bar{v}}{S+2 B} \equiv p^{*}
$$

Proof. In the Appendix.

As search frictions disappear, buyers become extremely choosy, and the price posted by the sellers depends on the relative measure of buyers and sellers. Interestingly, the decentralized equilibrium does not converge to the Walrasian equilibrium. The intuition for the result is as follows. Proposition 4 implies that removing search frictions induces both buyers and sellers to be choosy because there are more opportunities. Buyers will accept less for the same price, and this induces the sellers to cut their prices. However, the sellers also expect more trade opportunities, and this induces the sellers to raise their prices. The latter force continues to present even in the limit because the sellers are the price setters. Thus, sellers do not entirely lose their bargaining power in the frictionless limit. ${ }^{11}$ Similarly, the famous Diamond paradox does not arise either because the buyers' valuations are unobservable, so buyers do not lose their bargaining power.

Proposition 6 In the limit as $B / S \rightarrow 0, p \rightarrow c$. In the limit as $B / S \rightarrow \infty, p \rightarrow \bar{v}$.

\footnotetext{
${ }^{11}$ The term "bargaining power" is loosely used here even though prices are not negotiable. In this paper, bargaining power is referred to as the determinant of the division of trade surplus.
} 
Proof. In the Appendix.

Instead of removing search frictions, Proposition 6 considers the cases where the relative measure of sellers is infinite and zero. Even with search frictions and price posting, the decentralized equilibrium price becomes the unit cost of the product when the relative number of sellers is infinite. The reason is easily understood. From a buyer's point of view, the rate at which an acceptable offer arrives is infinite, so he can be extremely choosy. A seller, on the other hand, faces a ridiculously small rate of arrival of a buyer, and this drives her bargaining power to zero. The other result is understood in the same manner.

Finally, it is worth commenting on the implication of free entry. With free entry of sellers, the measure of sellers $S$ is determined so that $V_{s}=0$ holds. This immediately implies $p_{i}=c$ for all sellers. This point is somewhat related to the well-known result found in Gale (1987). One of the keys to obtaining the Walrasian outcome in the frictionless limit of search models is that potential traders can choose not to enter the market.

\section{Discussion}

\subsection{Ex-Post Bargaining with Observable Valuations}

In a related framework, Mortensen and Wright (2002) showed that their decentralized model converges to the Walrasian outcome as frictions disappear. They assumed ex-post bargaining with observable trade surplus.

Suppose the buyers' valuations are observable in the model developed in Section 2. With observable valuations and price setting, no seller has an incentive to set a price ex-ante. The price is determined ex-post such that the buyer is just indifferent between accepting and rejecting the trade. This would generate Diamond's (1971) result.

Now consider a more general case in which the buyer's valuations are observable and prices are determined by ex-post bilateral bargaining. I follow Mortensen and Wright (2002) to adopt the generalized Nash bargaining. ${ }^{12}$ The total net surplus of a certain pair is given by $v-c-V_{b}-V_{s} \equiv$

\footnotetext{
${ }^{12}$ To be more precise, they adopt a generalized Nash demand game (Osbourne and Rubinstein, 1990), in which
} 
$Y(v)$. Thus, the generalized Nash solution requires

$$
p_{i}=(1-\beta)\left[c+V_{s}\right]+\beta\left[v-V_{b}\right],
$$

where $\beta$ is the seller's (exogenous) share of total surplus. Note that $p_{i}$ depends on $v$. In other words, with observability of $v$, the price will be determined conditional on the realization of the buyer's valuation. With this pricing rule, the buyer obtains the net surplus of $(1-\beta) Y(v)$ and the seller obtains $\beta Y(v)$. Given a meeting, the buyer and seller agree a trade if and only if $Y(v) \geq 0$. Let $R$ be the reservation level of $v$. Thus, the Bellman equations for the buyer and seller are: $r V_{b}=(1-\beta) \alpha_{b} \int_{R}^{\bar{v}}[1-F(v)] d v$ and $r V_{s}=\beta \alpha_{s} \int_{R}^{\bar{v}}[1-F(v)] d v$, where $R=c+V_{b}+V_{s}$. Combine these equations to obtain $(R-c) r=\left[(1-\beta) \alpha_{b}+\beta \alpha_{s}\right] \int_{R}^{\bar{v}}[1-F(v)] d v$, which determines the unique $R$. The prices are generally dispersed because of the observable valuations and ex-post bargaining. What happens to the prices as search frictions disappear?

Proposition 7 In the limit as $r \rightarrow 0, R \rightarrow \bar{v}$ and

$$
p \rightarrow \frac{(1-\beta) S c+\beta B \bar{v}}{(1-\beta) S+\beta B} \equiv p^{b} .
$$

Proof. In the Appendix.

It is interesting to observe that although the law of one price is obtained as in Mortensen and Wright (2002), the price is not Walrasian. According to this expression, the price in the limit equals the Walrasian $(p=c)$ only if $\beta=0$ or $B \rightarrow 0$. In other words, removing search frictions is not enough to obtain the Walrasian outcome even in the model with observable valuations and ex-post bargaining. This suggests therefore that the key to the Walrasian outcome in this environment is the (potential) traders' exit option that is present in Mortensen and Wright (2002). Since the model developed in this paper rules out such an option, the model falls into the class of Rubinstein and Wolinsky (1985) rather than Gale (1987, 2000).

It is interesting to compare the prices $p^{*}$ and $p^{b}$ obtained above. It is easy to establish that

$$
p^{*}-p^{b}=\frac{(2-3 \beta) q(\bar{v}-v)}{(1+2 q)(1-\beta+\beta q)},
$$

the seller makes a take-it-or-leave-it offer with probability $\beta$. 
where $q \equiv B / S$. Thus, $p^{*} \geq p^{b}$ holds if and only if $\beta \leq 2 / 3$. In other words, the price posting with unobservable valuations amounts to the generalized Nash solution with the seller's bargaining power of $2 / 3$.

\subsection{Explicit Search Costs}

This paper regards the common discount rate $r$ as the (implicit) measure of search frictions. This interpretation, adopted in many models of decentralized trading, makes sense because the traders being perfectly patient amounts to saying that the traders make contact with each other at an infinite rate. However, in the literature of industrial organization with search frictions, it is common to adopt explicit search costs (Wolinsky, 1986; Stahl, 1989, 1996; Arbatskaya and Konishi, 2005).

Here, I briefly present a model in which the assumption of discounting is replaced with explicit search costs. The discrete-time versions of the Bellman equations (1) and (3) are

$$
\begin{aligned}
\delta & =\alpha_{b} \iint_{0}^{\bar{v}} \max \left\{v-p_{i}-V_{b}(p), 0\right\} d F(v) d G\left(p_{i}\right), \\
\delta & =\alpha_{s}[1-F(R)]\left[p_{i}-c-V_{s}\left(p_{i}, p\right)\right],
\end{aligned}
$$

respectively, and all notations should be reinterpreted accordingly. There is no discounting and traders must pay $\delta>0$ in each period instead. The reservation utility $R$ is given by $R=p_{i}+V_{b}(p)$. Then, (12) reduces to

$$
\delta=\alpha_{b} \int_{R}^{\bar{v}}[1-F(v)] d v,
$$

from which it is easy to verify that there is no room for manipulating the acceptability through prices; $R$ is pinned down by Equation (14).

\section{Market Share and Market Power}

\subsection{Monopoly}

In the previous sections, a seller is assumed to ignore how her price will affect the buyers' willingness to trade through its impact on their values of search. With this setup, it is evident that the seller 
faces a trade-off between price and acceptability. However, in equilibrium, higher prices induce the buyers to be less willing to purchase a commodity because they correctly believe that their values of search are higher. The key observation is that the failures to take into account the equilibrium impact of the prevailing price level on the buyers' values of search are a source of competition in this environment. If the sellers take into account this effect, will the sellers continue to face the trade-off between price and acceptability? Will equilibrium exist, and be unique? Will the sellers set higher prices than when they fail to take into account this effect?

To address the questions above, this section considers an environment in which there is a single monopolist consisting of a continuum of sellers. ${ }^{13}$ Note that this is different from an economy with $S \rightarrow 0$, in which a buyer rarely finds a potential trade partner. Here, a buyer can find a seller as easily as in the previous economy, but it is impossible to find competing sellers. In addition, the monopolist takes into account how the price influences the buyers' values of search because the monopolist regards the equilibrium price and each seller's price as the same thing.

In this economy, a buyer's value satisfies

$$
r V_{b}(p)=\alpha_{b} \int_{0}^{\bar{v}} \max \left\{v-p-V_{b}(p), 0\right\} d F(v) .
$$

Note that from the buyer's perspective, all sellers are the same. ${ }^{14}$ The reservation strategy is to accept a trade if and only if $v \geq R$, where $R=p+V_{b}(p)$. Given the reservation strategy, it is easy to rewrite the buyer's value as $r V_{b}(p)=\alpha_{b} \int_{R}^{\bar{v}}[1-F(v)] d v$. Substitute it back into $R=p+V_{b}(p)$ to obtain the equilibrium relationship between $p$ and $R: p=R-\left(\alpha_{b} / r\right) \int_{R}^{\bar{v}}[1-F(v)] d v \equiv H(R)$, which is identical to (8).

Consider the firm. The value of posting $p$ is given by $r V_{s}(p)=\alpha_{s}[1-F(R)]\left[p-c-V_{s}(p)\right]$. The firm chooses $p$ to maximize the value of search, taking into account the buyer's equilibrium reservation strategy. To be precise, the firm's problem is: $\max _{p} V_{s}(p)$ subject to $p=H(R)$.

\footnotetext{
${ }^{13}$ Early contributions on monopoly pricing with search frictions are found in Albrecht and Jovanovic (1986) and Wang (1995).

${ }^{14}$ This is the consequence of the buyers' beliefs that no seller will deviate from what the firm has decided. In this sense, it will be helpful to regard each seller as a vending machine.
} 
Proposition 8 The firm posts

$$
p=c+\frac{[1-F(R)]+\left(\alpha_{s} / r\right)[1-F(R)]^{2}}{F^{\prime}(R)} H^{\prime}(R) \equiv M(R) .
$$

Proof. In the Appendix.

Lemma $9 M(R)$ is decreasing if the distribution function satisfies (6).

Proof. In the Appendix.

A steady-state equilibrium with monopoly pricing is a set of posted price $p$ and reservation utility $R$ that satisfies $p=H(R)$ and $p=M(R)$. Then the price posting curve is downward sloping, and there is a unique steady state equilibrium. Since $H^{\prime}(R)>1$, it is easy to verify that $M(R)>P(R)$ holds for all $R$, as depicted in Figure 2. In this equilibrium, the price is higher and the buyers are choosier than in the model with a continuum of negligible sellers.

From a seller's perspective, if a buyer walks away, then this buyer will trade with someone else for sure. Thus, sellers become "myopic" (Reinganum, 1982). This introduces some competition among sellers, and a seller has an incentive to reduce the price. On the other hand, in the monopoly case, all sellers belong to a single firm, and the firm knows that even though a buyer walks away from a particular seller, this buyer will have to trade with another seller from the same firm. This gives the firm more bargaining power, leading to a higher price. However, the buyers do not entirely lose their bargaining power because their valuations are unobservable and they always have the options to postpone consumption.

\subsection{Oligopoly}

An important issue in price theory is to explain the Bertrand Paradox and the Diamond Paradox. The former states that two firms are enough to generate the perfectly competitive outcome in the Bertrand price competition model. The latter states that even with a large number of firms, there will be no price competition among firms as long as each buyer faces a small search cost. As pointed out by Gale (1988), the difference in the two models is, in principle, the order of play: in the former, buyers choose which store to go to after observing the prices; in the latter, buyers visit 
sellers before their prices are quoted. The question addressed in this section is therefore as follows. If there is a finite (countable) number of firms in this decentralized economy with search frictions, how competitive will the prices be?

Suppose there are $N$ firms, each consisting of a continuum of sellers. Each firm is considered to be a coalition of sellers that pools the values of all members, and it sets the price on behalf of the members. ${ }^{15}$ Let $j=1, \ldots, N$ index each firm. The basic idea behind this formulation is that the market power of a certain firm is captured by the size of the coalition; as the size of coalition approaches 1, the firm becomes more monopolistic (in the sense of the model in the previous section). The fraction of sellers belonging to firm $j$ is denoted by $\theta_{j}$, and is conveniently referred to as the "market share" or the degree of dominance. Evidently, $\sum_{j=1}^{N} \theta_{j}=1$. I assume that all sellers of firm $j$ follow the same strategy and therefore set the same price $p_{j}$.

Consider a buyer's decision. A buyer meets a seller with probability $\alpha_{b}$, and this seller happens to belong to firm $j$ with probability $\theta_{j}$. The buyer observes $v$, and agrees to a trade if and only if the gains from the trade exceed the value of continuing the search. Thus, the value of search $V_{b}$ satisfies

$$
r V_{b}\left(p_{1}, \ldots, p_{N}\right)=\alpha_{b} \sum_{j=1}^{N} \theta_{j} \int_{0}^{\bar{v}} \max \left\{v-p_{j}-V_{b}\left(p_{1}, \ldots, p_{N}\right), 0\right\} d F(v) .
$$

The buyer accepts a trade if and only if $v \geq R_{j}$ holds, where $R_{j}=p_{j}+V_{b}\left(p_{1}, \ldots, p_{N}\right)$. In other words, the buyer forms a reservation utility for each firm. Given these reservation strategies,

$$
V_{b}\left(p_{1}, \ldots, p_{N}\right)=\frac{\alpha_{b}}{r} \sum_{j=1}^{N} \theta_{j} \int_{R_{j}}^{\bar{v}}[1-F(v)] d v \equiv \Omega\left(R_{1}, \ldots, R_{N}\right) .
$$

Substitute this back into the cutoff condition to obtain

$$
p_{j}=R_{j}-\Omega\left(R_{1}, \ldots, R_{N}\right)
$$

for $j=1, \ldots, N$. This summarizes the trade-off that each firm faces. It is easy to show that $\partial p_{j} / \partial R_{j}=1+\left(\alpha_{b} / r\right) \theta_{j}\left[1-F\left(R_{j}\right)\right]<H^{\prime}\left(R_{j}\right)$ because $\theta_{j} \in(0,1)$. This implies that an oligopolistic firm internalizes partially the effect of a price change on the equilibrium price.

\footnotetext{
${ }^{15} \mathrm{As}$ in the previous section, it is appropriate to regard each seller as a vending machine. The idea that each trader belongs to a coalition in a search environment first appears in Shi (1997). In Shi (1998), prices are determined in a decentralized manner.
} 
The value of a seller belonging to firm $j$ satisfies

$$
r V_{s}^{j}\left(p_{j}\right)=\alpha_{s}\left[1-F\left(R_{j}\right)\right]\left[p_{j}-c-V_{s}^{j}\left(p_{j}\right)\right]
$$

Thus, the pricing problem for firm $j$ is $\max _{p_{j}} V_{s}^{j}\left(p_{j}\right)$ subject to (16), taking all other firms' prices as given.

Proposition 10 Each firm $j(j=1, \ldots, N)$ posts

$$
p_{j}=c+\frac{\left[1-F\left(R_{j}\right)\right]+\left(\alpha_{s} / r\right)\left[1-F\left(R_{j}\right)\right]^{2}}{F^{\prime}\left(R_{j}\right)}\left[1+\left(\alpha_{b} / r\right) \theta_{j}\left[1-F\left(R_{j}\right)\right]\right] \equiv L_{j}\left(R_{j}\right) .
$$

The problem can be solved similarly as in Proposition 8. $H^{\prime}(R)$ in (15) is replaced with $1+$ $\left(\alpha_{b} / r\right) \theta_{j}\left[1-F\left(R_{j}\right)\right]$, which captures the degree of market power: if $\theta_{j}=0$ then the pricing behavior coincides with a single (infinitesimal) seller in the basic model; if $\theta_{j}=1$ then this corresponds to the monopoly case. From (18), it is easy to show that $\partial p_{j} / \partial \theta_{j}>0$, which suggests that larger firms (in terms of the market share) have incentives to set higher prices.

Market equilibrium is defined as a set of prices and reservation strategies such that (16) and (18) are satisfied. Consider the symmetric equilibrium in which all firms have the same size $\left(\theta_{j}=S / N\right.$ for all $j$ ). As $N \rightarrow \infty$, the equilibrium approaches the one with a continuum of negligible sellers. As $N \rightarrow S$, the equilibrium approaches the one with a monopolist.

In what follows, I focus on the duopoly case $(N=2)$. An equilibrium is given by $p_{j}=$ $R_{j}-\Omega\left(R_{1}, R_{2}\right)$ and $p_{j}=L_{j}\left(R_{j}\right)$ for $j=1,2$. From (16),

$$
p_{1}-p_{2}=R_{1}-R_{2}
$$

which implies $p_{1}>p_{2} \Leftrightarrow R_{1}>R_{2}$. Since $L_{j}\left(R_{j}\right)$ is monotone-decreasing, $p_{j}=L_{j}\left(R_{j}\right)$ implies $R_{j}=L_{j}^{-1}\left(p_{j}\right)$, where $L_{j}^{-1}$ is the inverse of $L_{j}$. Substitute this into the other equation to obtain

$$
\begin{aligned}
& p_{1}=L_{1}^{-1}\left(p_{1}\right)-\Omega\left(L_{1}^{-1}\left(p_{1}\right), L_{2}^{-1}\left(p_{2}\right)\right) \\
& p_{2}=L_{2}^{-1}\left(p_{2}\right)-\Omega\left(L_{1}^{-1}\left(p_{1}\right), L_{2}^{-1}\left(p_{2}\right)\right)
\end{aligned}
$$

The equilibrium is given by a pair $\left(p_{1}, p_{2}\right)$ that solves $(20)$ and (21). These expressions implicitly define $p_{1}=\mu_{1}\left(p_{2}\right)$ and $p_{2}=\mu_{2}\left(p_{1}\right)$, from which it is possible to show the following: 
Lemma $11 \mu_{1}^{\prime}\left(p_{2}\right)<0$ and $\mu_{2}^{\prime}\left(p_{1}\right)<0$.

Proof. In the Appendix.

It is now evident that the firms' actions are strategic substitutes. The intuition for the result is as follows. Suppose firm 1 reduces its price. The direct effect is that buyers become more willing to purchase from sellers of firm 1 . The indirect effect is that a decrease in $p_{1}$ increases the buyers' values of search. This makes the buyers less willing to purchase from sellers of both firms. Firm 2's optimal reaction to this is to raise the price slightly to offset the increase in the buyers' values of search.

Proposition 12 An increase in the size of a firm raises its price and reduces the rival's price.

Proof. In the Appendix.

Corollary 13 There is price dispersion unless $\theta_{1}=\theta_{2}=1 / 2$.

As a firm gets larger, its market power increases and it sets a higher price than its rival firm. Accordingly, two different prices are possible in the search equilibrium. This suggests a new explanation for price dispersion, namely, search frictions combined with oligopolistic competition. Interestingly, the property of the equilibrium is closer to the one of the Cournot model than that of the Bertrand model, even though the firms compete by choosing their prices. An important lesson here is that price competition per se is not the key. Rather, as clarified by Gale (1988), what matters is whether the buyers can choose which firm to go to after the prices are quoted.

\section{Conclusion}

This paper developed a simple random search model with price posting in which the sellers face a trade-off between price and the buyer's willingness to trade, and the trade-off is derived naturally from the basics of the model. The trade-off between price and the willingness to trade has not been observed in the consumer search models without discounting. In this sense, the trade-off found in this paper is dynamic in nature. To demonstrate the usefulness of the model, monopoly and 
oligopoly have been studied. It has been shown that price dispersion arises as a result of search frictions and price setting, and this is new to the literature.

This paper has focused on a stationary equilibrium by assuming that a buyer who completed a transaction is replaced with a clone. Although this is a fairly standard assumption in search theory, it introduces some nontrivial implications into the analysis. One is that the framework becomes non-Walrasian even in the limit as search frictions disappear. Another important implication is that supply creates its own demand in the sense that if sellers cut prices then they can expect the aggregate demand to increase without reducing the future demand. In other words, there is assumed to be no intertemporal trade-off of demands. A possible extension of this analysis is to consider a nonstationary environment in the spirit of Fershtman and Fishman (1992) so as to introduce the mechanism where the future aggregate demand decreases if the buyers' current consumptions are high.

This paper has maintained the assumption of random search. As stated briefly in the Introduction, an important development has been observed in the field of directed search theory, which is by construction more competitive than a random search environment. It will be worthwhile to explore whether the Cournot outcome continues to hold in the duopoly model with directed search using the model developed in this paper. 


\section{Appendix}

\section{A Proof of Proposition 1}

The first-order condition for the maximization problem of the right-hand side (4) is given by $\alpha_{s}[1-F(R)]\left[1-\partial V_{s}\left(p_{i}, p\right) / \partial p_{i}\right]-\alpha_{s} F^{\prime}(R)\left[p_{i}-c-V_{s}\left(p_{i}, p\right)\right]=0$. The Envelope Theorem implies $\partial V_{s}\left(p_{i}, p\right) / \partial p_{i}=0$, so

$$
[1-F(R)]=F^{\prime}(R)\left[p_{i}-c-V_{s}\left(p_{i}, p\right)\right]
$$

Solve (3) for $V_{s}$ and substitute it into (22) to obtain the price $p_{i}$ as a function of $R$. The secondorder condition is $-2 F^{\prime}(R)-F^{\prime \prime}(R)\left[p_{i}-c-V_{s}\left(p_{i}, p\right)\right]<0$. Use the first-order condition to rewrite it as $C(R)<2$, where $C(R)=F^{\prime \prime}(R) F^{\prime}(R)^{-2}[1-F(R)]$. To verify that this function is decreasing, differentiate (5) to obtain

$$
P^{\prime}(R)=-\left[1+\left(\alpha_{s} / r\right)[1-F(R)]\right][1+C(R)]-\left(\alpha_{s} / r\right)[1-F(R)]
$$

Thus, it is evident that a sufficient condition for the existence of decreasing $P(R)$ is $-1<C(R)<2$.

\section{B Proof of Proposition 3}

Lemma 2 establishes that $H(R)$ is increasing. From Proposition 1, $P(R)$ is decreasing if $(6)$ holds. From (8) and (5), $P(0)>H(0)$ because $c+\left[1+\left(\alpha_{s} / r\right)\right] F^{\prime}(0)^{-1}>-\left(\alpha_{b} / r\right) \int_{0}^{\bar{v}}[1-F(v)] d v$ holds for $F^{\prime}(0) \geq 0$. That is, $P(0)>H(0)$ holds under any density $F^{\prime}(v)>0$. Finally, $P(\bar{v})-H(\bar{v})=$ $c+0 / F^{\prime}(\bar{v})-\bar{v}<0$ holds if $F^{\prime}(\bar{v})>0$ and $c<\bar{v}$. The term $0 / F^{\prime}(\bar{v})$ is not well-defined in the case of $F^{\prime}(\bar{v})=0$. Applying l'Hopital's rule, it is easy to verify that

$$
P(\bar{v})-H(\bar{v})=c+\lim _{R \rightarrow \bar{v}} \frac{-F^{\prime}(R)-2\left(\alpha_{s} / r\right)[1-F(R)] F^{\prime \prime}(R)}{F^{\prime \prime}(R)}-\bar{v}=c-\bar{v}<0 .
$$

This establishes the existence and uniqueness of equilibrium under the maintained assumptions $c<\bar{v}$ and (6). 


\section{Proof of Proposition 4}

From (5), $\partial P / \partial r=-\alpha_{s}[1-F(R)]^{2} /\left[r^{2} F^{\prime}(R)\right]<0$ and $P^{\prime}(R)$ is given by (23). Similarly, from (8), $\partial H / \partial r=\left(\alpha_{b} / r^{2}\right) \int_{R}^{\bar{v}}[1-F(v)] d v>0$ and $H^{\prime}(R)=1+\left(\alpha_{b} / r\right)[1-F(R)]>0$. (a) From (5) and (8), it is easy to verify that an increase in $r$ will shift the $p=P(R)$ locus downward and $p=H(R)$ locus upward in Figure 1. Thus, $R$ will unambiguously decrease. (b) Totally differentiate (5) and (8) to obtain $d p=P^{\prime}(R) d R+[\partial P(R) / \partial r] d r$ and $d p=H^{\prime}(R) d R+[\partial H(R) / \partial r] d r$. Thus,

$$
\left[1-\frac{P^{\prime}(R)}{H^{\prime}(R)}\right] \frac{d p}{d r}=\frac{\partial P(R)}{\partial r}-\frac{P^{\prime}(R)}{H^{\prime}(R)} \frac{\partial H(R)}{\partial r} .
$$

Since $P^{\prime}(R)<0<H^{\prime}(R)$, the left-hand side of this expression is positive. Thus, $d p / d r>0$ holds if and only if its right-hand side is positive, or $[\partial P(R) / \partial r] /[\partial H(R) / \partial r]>P^{\prime}(R) / H^{\prime}(R)$, or

$$
\frac{-[1-F(R)]^{2}}{F^{\prime}(R) \int_{R}^{\bar{v}}[1-F(v)] d v}>\frac{\alpha_{b}}{\alpha_{s}} \frac{-\left[r+\alpha_{s}[1-F(R)]\right][1+C(R)]-\alpha_{s}[1-F(R)]}{r+\alpha_{b}[1-F(R)]} .
$$

Thus, the effect is ambiguous. (c) Let $q \equiv B / S$ for convenience. From (5) and (8), it is easy to obtain

$$
\frac{\partial P}{\partial q}=\frac{[1-F(R)]^{2}}{r F^{\prime}(R)} \frac{\partial \alpha_{s}}{\partial q}>0, \frac{\partial H}{\partial q}=-\frac{1}{r}\left(\int_{R}^{\bar{v}}[1-F(v)] d v\right) \frac{\partial \alpha_{b}}{\partial q}>0 .
$$

From Figure 1 it is easy to establish that $d p / d q>0$. Totally differentiate (5) and (8) to obtain $\left[P^{\prime}(R)-H^{\prime}(R)\right] d R / d q=\partial H(R) / \partial q-\partial P(R) / \partial q$. Since $P^{\prime}(R)-H^{\prime}(R)<0, d R / d q>0$ if and only if

$$
-\left(\int_{R}^{\bar{v}}[1-F(v)] d v\right) \frac{\partial \alpha_{b}}{\partial q}<\frac{[1-F(R)]^{2}}{F^{\prime}(R)} \frac{\partial \alpha_{s}}{\partial q} .
$$

Thus, the effect is ambiguous.

\section{Proof of Proposition 5}

From $(7), V_{b}=\left(\alpha_{b} / r\right) \int_{R}^{\bar{v}}[1-F(v)] d v$. Since $V_{b}$ is bounded, as $r \rightarrow 0, \int_{R}^{\bar{v}}[1-F(v)] d v$ must converge to zero. This implies $R \rightarrow \bar{v}$ ad $r \rightarrow 0$. In what follows I denote $R=R(r)$. Consider (5). Take the limit on the right-hand side:

$$
\lim _{r \rightarrow 0} P(R)=c+\frac{1-F(\bar{v})}{F^{\prime}(\bar{v})}+\lim _{r \rightarrow 0} \frac{\alpha_{s}[1-F(R(r))]^{2}}{r F^{\prime}(R(r))} .
$$


Since $F^{\prime}(\bar{v})>0$, the second term on the right-hand side of (24) is zero. Apply l'Hopital's rule to the third term and obtain

$$
\begin{aligned}
\lim _{r \rightarrow 0} P(R(r)) & =c+\alpha_{s} \lim _{r \rightarrow 0}\left\{\frac{-2[1-F(R(r))]\left[F^{\prime}(R(r))\right]^{2}-[1-F(R(r))]^{2} F^{\prime \prime}(R(r))}{\left[F^{\prime}(R(r))\right]^{2}} R^{\prime}(r)\right\} \\
& =c-\alpha_{s} \lim _{r \rightarrow 0}[2+C(R(r))][1-F(R(r))] R^{\prime}(r)
\end{aligned}
$$

where $C(R)=F^{\prime \prime}(R)[1-F(R)] / F^{\prime}(R)^{2}>-1$ and $R^{\prime}(r)<0$. Similarly, from (8),

$$
\lim _{r \rightarrow 0} H(R(r))=\bar{v}-\alpha_{b} \lim _{r \rightarrow 0} \frac{\int_{R(r)}^{\bar{v}}[1-F(v)] d v}{r}=\bar{v}-\alpha_{b} \lim _{r \rightarrow 0} \frac{-[1-F(R(r))] R^{\prime}(r)}{1} .
$$

Thus, the posted price in the limit, denoted by $p^{*}$, satisfies

$$
\begin{aligned}
& p^{*}=c-\alpha_{s} \lim _{r \rightarrow 0}[2+C(R(r))][1-F(R(r))] R^{\prime}(r), \\
& p^{*}=\bar{v}+\alpha_{b} \lim _{r \rightarrow 0}[1-F(R(r))] R^{\prime}(r) .
\end{aligned}
$$

Suppose that $\lim _{r \rightarrow 0}[1-F(R(r))] R^{\prime}(r)=0$. Then (25) and (26) imply $p^{*}=c$ and $p^{*}=\bar{v}$, a contradiction. Similarly, it cannot be $-\infty$. Thus, $[1-F(R(r))] R^{\prime}(r)$ must converge to some number $k \in(-\infty, 0)$. Note that $\lim _{r \rightarrow 0}[2+C(R(r))]=2$. With convergence, $(25)$ may be written as $p^{*}=c-\alpha_{s} \lim _{r \rightarrow 0}[2+C(R(r))] \lim _{r \rightarrow 0}[1-F(R(r))] R^{\prime}(r)$. Thus, $p^{*}$ must satisfy $p^{*}=c-\alpha_{s} 2 k=$ $c-q \alpha_{b} 2 k$ and $p^{*}=\bar{v}+\alpha_{b} k$. Eliminate $k$ from these expressions to obtain the desired result.

\section{E Proof of Proposition 6}

Note that as $B / S \rightarrow 0, \alpha_{b} \rightarrow \infty$ and $\alpha_{s} \rightarrow 0$. From $(7), V_{b}=\left(\alpha_{b} / r\right) \int_{R}^{\bar{v}}[1-F(v)] d v$. Since $V_{b}$ is bounded, as $\alpha_{b} \rightarrow \infty, \int_{R}^{\bar{v}}[1-F(v)] d v$ must converge to zero. This implies $R \rightarrow \bar{v}$. From (5)

$$
p_{i} \rightarrow c+\frac{1-F(\bar{v})}{F^{\prime}(\bar{v})}=c .
$$

Similarly, as $B / S \rightarrow \infty, \alpha_{b} \rightarrow 0$ and $\alpha_{s} \rightarrow \infty$. Then, (7) implies that $V_{b} \rightarrow 0$ and $R \rightarrow p_{i}$. In other words, a buyer will accept a trade if the value of the good exceeds its price. Since the seller's value of search must be bounded, (3) implies that as $\alpha_{s} \rightarrow \infty, p_{i} \rightarrow \bar{v}$. In other words, each seller posts the price at the buyer's maximum willingness to pay, since the seller faces no frictions in this limit. 


\section{F $\quad$ Proof of Proposition 7}

The equilibrium is characterized by $r V_{b}=(1-\beta) \alpha_{b} \int_{R}^{\bar{v}}[1-F(v)] d v, r V_{s}=\beta \alpha_{s} \int_{R}^{\bar{v}}[1-F(v)] d v$, and $(R-c) r=\left[(1-\beta) \alpha_{b}+\beta \alpha_{s}\right] \int_{R}^{\bar{v}}[1-F(v)] d v$. It is evident from the Bellman equations that as $r \rightarrow 0, R \rightarrow \bar{v}$. That is, traders become extremely choosy. Thus, trades are possible only when $v=\bar{v}$, implying from (11) that there will be no price dispersion. Let $(1 / r) \int_{R}^{\bar{v}}[1-F(v)] d v \equiv K$ and eliminate $K$ from the expressions above to obtain

$$
\lim _{r \rightarrow 0} V_{b}=\frac{(1-\beta) \alpha_{b}(\bar{v}-c)}{(1-\beta) \alpha_{b}+\beta \alpha_{s}}, \lim _{r \rightarrow 0} V_{s}=\frac{\beta \alpha_{s}(\bar{v}-c)}{(1-\beta) \alpha_{b}+\beta \alpha_{s}} .
$$

Substitute these into (11) to obtain

$$
\lim _{r \rightarrow 0} p_{i}=\frac{c(1-\beta) \alpha_{b}+\beta \bar{v} \alpha_{s}}{(1-\beta) \alpha_{b}+\beta \alpha_{s}}=\frac{c(1-\beta) S+\beta \bar{v} B}{(1-\beta) S+\beta B} .
$$

\section{G Proof of Proposition 8}

The Lagrangian for this problem is $\alpha_{s}[1-F(R)]\left[p-c-V_{s}(p)\right]+\lambda[H(R)-p]$, where $\lambda$ is the Lagrangian multiplier. The first-order conditions with respect to $p$ and $R$ are $\alpha_{s}[1-F(R)][1-$ $\left.V_{s}^{\prime}(p)\right]=\lambda$ and $\alpha_{s} F^{\prime}(R)\left[p-c-V_{s}(p)\right]=\lambda H^{\prime}(R)$, respectively. Thus,

$$
\frac{F^{\prime}(R)}{1-F(R)}\left[p-c-V_{s}(p)\right]=H^{\prime}(R) .
$$

Solve $r V_{s}(p)=\alpha_{s}[1-F(R)]\left[p-c-V_{s}(p)\right]$ for $V_{s}(p)$ and substitute it into (27) to obtain

$$
\frac{F^{\prime}(R)}{1-F(R)} \frac{r(p-c)}{r+\alpha_{s}[1-F(R)]}=H^{\prime}(R) \text {. }
$$

Solve this equation for $p$ to obtain the desired result.

\section{H Proof of Lemma 9}

Consider $p=M(R)=c+T(R) H^{\prime}(R)$, where $T(R) \equiv\left\{[1-F(R)]+\left(\alpha_{s} / r\right)[1-F(R)]^{2}\right\} / F^{\prime}(R)>0$. Since $M^{\prime}(R)=T^{\prime}(R) H^{\prime}(R)+T(R) H^{\prime \prime}(R)$, Lemma 2 implies that $M^{\prime}(R)<0$ holds if $T^{\prime}(R)<0$. From the argument in Proposition 1, a sufficient condition for $T^{\prime}(R)<0$ is $-[1-F(R)]^{-1}\left[F^{\prime}(R)\right]^{2}<$ $F^{\prime \prime}(R)$. 


\section{Proof of Lemma 11}

The steady-state equilibrium is characterized by (20) and (21). To be more precise,

$$
\begin{aligned}
& p_{1}=L_{1}^{-1}\left(p_{1}\right)-\frac{\alpha_{b}}{r} \theta_{1} \int_{L_{1}^{-1}\left(p_{1}\right)}^{\bar{v}}[1-F(v)] d v-\frac{\alpha_{b}}{r} \theta_{2} \int_{L_{2}^{-1}\left(p_{2}\right)}^{\bar{v}}[1-F(v)] d v, \\
& p_{2}=L_{2}^{-1}\left(p_{2}\right)-\frac{\alpha_{b}}{r} \theta_{1} \int_{L_{1}^{-1}\left(p_{1}\right)}^{\bar{v}}[1-F(v)] d v-\frac{\alpha_{b}}{r} \theta_{2} \int_{L_{2}^{-1}\left(p_{2}\right)}^{\bar{v}}[1-F(v)] d v .
\end{aligned}
$$

Totally differentiate these equations to obtain

$$
\begin{aligned}
\frac{d p_{1}}{d p_{2}} & =\frac{\frac{\alpha_{b}}{r} \theta_{2}\left[1-F\left(L_{2}^{-1}\left(p_{2}\right)\right)\right] \frac{\partial L_{2}^{-1}\left(p_{2}\right)}{\partial p_{2}}}{1-\left\{1+\frac{\alpha_{b}}{r} \theta_{1}\left[1-F\left(L_{1}^{-1}\left(p_{1}\right)\right)\right]\right\} \frac{\partial L_{1}^{-1}\left(p_{1}\right)}{\partial p_{1}}}, \\
\frac{d p_{2}}{d p_{1}} & =\frac{\frac{\alpha_{b}}{r} \theta_{1}\left[1-F\left(L_{1}^{-1}\left(p_{1}\right)\right)\right] \frac{\partial L_{1}^{-1}\left(p_{1}\right)}{\partial p_{1}}}{1-\left\{1+\frac{\alpha_{b}}{r} \theta_{2}\left[1-F\left(L_{2}^{-1}\left(p_{2}\right)\right)\right]\right\} \frac{\partial L_{2}^{-1}\left(p_{2}\right)}{\partial p_{2}}},
\end{aligned}
$$

where

$$
\frac{\partial L_{1}^{-1}\left(p_{1}\right)}{\partial p_{1}}=\frac{1}{L_{1}^{\prime}\left(L_{1}^{-1}\left(p_{1}\right)\right)}<0, \frac{\partial L_{2}^{-1}\left(p_{2}\right)}{\partial p_{2}}=\frac{1}{L_{2}^{\prime}\left(L_{2}^{-1}\left(p_{2}\right)\right)}<0 .
$$

Thus, $d p_{1} / d p_{2}<0$ and $d p_{2} / d p_{1}<0$.

\section{J Proof of Proposition 12}

Instead of working directly with prices, I shall work with $R_{1}$ and $R_{2}$. Then the equilibrium is characterized by a pair $\left(R_{1}, R_{2}\right)$ such that

$$
\begin{aligned}
& R_{j}-\frac{\alpha_{b}}{r} \theta_{1} \int_{R_{1}}^{\bar{v}}[1-F(v)] d v-\frac{\alpha_{b}}{r}\left(1-\theta_{1}\right) \int_{R_{2}}^{\bar{v}}[1-F(v)] d v \\
= & c+\tilde{P}\left(R_{j}\right)\left[1+\left(\alpha_{b} / r\right) \theta_{j}\left[1-F\left(R_{j}\right)\right]\right]
\end{aligned}
$$

for $j=1,2$, where

$$
\tilde{P}\left(R_{j}\right)=\frac{\left[1-F\left(R_{j}\right)\right]+\left(\alpha_{s} / r\right)\left[1-F\left(R_{j}\right)\right]^{2}}{F^{\prime}\left(R_{j}\right)}=P\left(R_{j}\right)-c, \tilde{P}^{\prime}\left(R_{j}\right)<0 .
$$

Totally differentiate these expressions and arrange terms to obtain

$$
\begin{aligned}
& \frac{\alpha_{b}}{r}\left(1-\theta_{1}\right)\left[1-F\left(R_{2}\right)\right] d R_{2}=\tilde{P}^{\prime}\left(R_{1}\right)\left[1+\left(\alpha_{b} / r\right) \theta_{1}\left[1-F\left(R_{1}\right)\right]\right] d R_{1} \\
& -\tilde{P}\left(R_{1}\right)\left(\alpha_{b} / r\right) \theta_{1} F^{\prime}\left(R_{1}\right) d R_{1}-d R_{1}-\frac{\alpha_{b}}{r} \theta_{1}\left[1-F\left(R_{1}\right)\right] d R_{1} \\
& +\tilde{P}\left(R_{1}\right)\left(\alpha_{b} / r\right)\left[1-F\left(R_{1}\right)\right] d \theta_{1}+\frac{\alpha_{b}}{r} \int_{R_{1}}^{R_{2}}[1-F(v)] d v d \theta_{1},
\end{aligned}
$$


and

$$
\begin{aligned}
& \frac{\alpha_{b}}{r} \theta_{1}\left[1-F\left(R_{1}\right)\right] d R_{1}=\tilde{P}^{\prime}\left(R_{2}\right)\left[1+\left(\alpha_{b} / r\right)\left(1-\theta_{1}\right)\left[1-F\left(R_{2}\right)\right]\right] d R_{2} \\
& -\tilde{P}\left(R_{2}\right)\left(\alpha_{b} / r\right)\left(1-\theta_{1}\right) F^{\prime}\left(R_{2}\right) d R_{2}-d R_{2}-\frac{\alpha_{b}}{r}\left(1-\theta_{1}\right)\left[1-F\left(R_{2}\right)\right] d R_{2} \\
& -\tilde{P}\left(R_{2}\right)\left(\alpha_{b} / r\right)\left[1-F\left(R_{2}\right)\right] d \theta_{1}+\frac{\alpha_{b}}{r} \int_{R_{1}}^{R_{2}}[1-F(v)] d v d \theta_{1},
\end{aligned}
$$

which reduce to $X_{1} d R_{2}=-X_{2} d R_{1}+X_{3} d \theta_{1}$ and $X_{4} d R_{1}=-X_{5} d R_{2}+X_{6} d \theta_{1}$, where $X_{1}, X_{2}, X_{4}, X_{5} \geq$ 0 . It is then easy to show that

$$
\frac{d R_{1}}{d \theta_{1}}=\frac{X_{1} X_{6}-X_{5} X_{3}}{X_{1} X_{4}-X_{5} X_{2}}, \frac{d R_{2}}{d \theta_{1}}=\frac{X_{4} X_{3}-X_{2} X_{6}}{X_{1} X_{4}-X_{5} X_{2}}
$$

where $X_{1} X_{4}-X_{5} X_{2} \leq 0$. It is easy, though tedious, to verify that $X_{1} X_{6}-X_{5} X_{3} \leq 0$ holds if $\tilde{P}\left(R_{1}\right)\left[1-F\left(R_{1}\right)\right]+\int_{R_{1}}^{R_{2}}[1-F(v)] d v \geq 0$. Apply Taylor approximation on the second term and rewrite this inequality as $\tilde{P}\left(R_{1}\right)\left[1-F\left(R_{1}\right)\right]+\left[1-F\left(R_{1}\right)\right]\left(R_{2}-R_{1}\right) \geq 0$, or $\tilde{P}\left(R_{1}\right)+R_{2}-R_{1} \geq 0$. Since by definition $\tilde{P}\left(R_{1}\right)=p_{1}-c$, this inequality reduces to $p_{1}-c+R_{2}-R_{1} \geq 0$. Use $p_{1}-p_{2}=R_{1}-R_{2}$ to rewrite it further as $p_{1}-c+R_{2}-R_{1}=p_{2}-c \geq 0$, which must hold in any equilibrium. This proves $X_{1} X_{6}-X_{5} X_{3} \leq 0$ and therefore $d R_{1} / d \theta_{1} \geq 0$. Similarly, $X_{4} X_{3}-X_{2} X_{6} \geq 0$ holds if $\tilde{P}\left(R_{2}\right)\left[1-F\left(R_{2}\right)\right]-\int_{R_{1}}^{R_{2}}[1-F(v)] d v \geq 0$. Apply Taylor approximation on the second term and rewrite this inequality as $\tilde{P}\left(R_{2}\right)\left[1-F\left(R_{2}\right)\right]-\left[1-F\left(R_{2}\right)\right]\left(R_{2}-R_{1}\right) \geq 0$, which reduces to $p_{2}-c-R_{2}+R_{1} \geq 0$, which further reduces to $p_{1}-c \geq 0$. This proves $X_{4} X_{3}-X_{2} X_{6} \geq 0$ and therefore $d R_{2} / d \theta_{1} \leq 0$. Thus, higher $R$ are associated with higher $\theta$. Since $p_{1}-p_{2}=R_{1}-R_{2}$, this amounts to saying that higher prices are associated with larger coalition sizes. 


\section{References}

[1] Acemoglu, Daron, and Robert Shimer. "Holdups and Efficiency with Search Frictions", International Economic Review 40 (1999) 827-849.

[2] Albrecht, James, and Boyan Jovanovic. "The Efficiency of Search under Competition and Monopsony", Journal of Political Economy 94 (1986) 1246-1257.

[3] Arbatskaya, Maria, and Hideo Konishi. "Referrals in Search Markets," mimeo, 2005.

[4] Bagnoli, Mark, and Ted Bergstrom. "Log-concave Probability and Its Applications", Economic Theory 26 (2005) 445-469.

[5] Bester, Helmut. "Price Commitment in Search Markets", Journal of Economic Behavior and Organization 25 (1994) 109-120.

[6] Burdett, Kenneth, and Randall Wright. "Two-Sided Search with Nontransferable Utility", Review of Economic Dynamics 1 (1998) 220-45.

[7] Curtis, Elisabeth, and Randall Wright. "Price Setting, Price Dispersion, and the Value of Money: or, the Law of Two Prices", Journal of Monetary Economics 51 (2004) 1599-1621.

[8] De Fraja, Gianni, and József Sákovics. "Walras Retrouvé: Decentralized Trading Mechanisms and the Competitive Price", Journal of Political Economy 109 (2001) 842-863.

[9] Diamond, Peter A. "A Model of Price Adjustment", Journal of Economic Theory 3 (1971) $156-168$.

[10] Fershtman, Chaim, and Arthur Fishman. "Price Cycles and Booms: Dynamic Search Equilibrium", American Economic Review 82 (1992) 1221-1233.

[11] Gale, Douglas. "Limit Theorems for Markets with Sequential Bargaining", Journal of Economic Theory 43 (1987) 20-54. 
[12] Gale, Douglas. "Price Setting and Competition in a Simple Duopoly Model", Quarterly Journal of Economics 103 (1988) 729-739.

[13] Gale, Douglas. Strategic Foundations of General Equilibrium: Dynamic Matching and Bargaining Games, Cambridge University Press, Cambridge, 2000.

[14] Masters, Adrian M. "Wage Posting in Two-Sided Search and the Minimum Wage", International Economic Review 40 (1999) 809-26.

[15] Mortensen, Dale T. and Randall Wright. "Competitive Pricing and Efficiency in Search Equilibrium", International Economic Review 43 (2002) 1-20.

[16] Osborne, Martin J., and Ariel Rubinstein. Bargaining and Markets. Academic Press, San Diego, 1990.

[17] Reingnum, Jennifer F. "Strategic Search Theory", International Economic Review 23 (1982) $1-17$.

[18] Rogerson, Richard, Robert Shimer, and Randall Wright. "Search-Theoretic Models of the Labor Market: A Survey," Journal of Economic Literature 18 (2005) 959-988.

[19] Rubinstein, Ariel, and Asher Wolinsky. "Equilibrium in a Market with Sequential Bargaining", Econometrica 53 (1985) 1133-1150.

[20] Shi, Shouyong. "A Divisible Search Model of Fiat Money," Econometrica 65 (1997) 75-102.

[21] Stahl, Dale O. "Oligopolistic Pricing with Sequential Consumer Search", American Economic Review 79 (1989) 700-712.

[22] Stahl, Dale O. "Oligopolistic Pricing with Heterogeneous Consumer Search", International Journal of Industrial Organization 14 (1996) 243-268.

[23] Wang, Ruqu. "Bargaining versus Posted-price Selling", European Economic Review 39 (1995) $1747-1764$. 
[24] Wilson, Robert. "Game-theoretic Analyses of Trading Processes", in, Truman F. Bewley (editor) Advances in Economic Theory: Fifth World Congress, Cambridge University Press, Cambridge, 1987.

[25] Wolinsky, Asher. "True Monopolistic Competition as a Result of Imperfect Information", Quarterly Journal of Economics 101 (1986) 493-512.

[26] Wolinsky, Asher. "Dynamic Markets with Competitive Bidding", Review of Economic Studies $55(1988) 71-84$. 
Figure 1

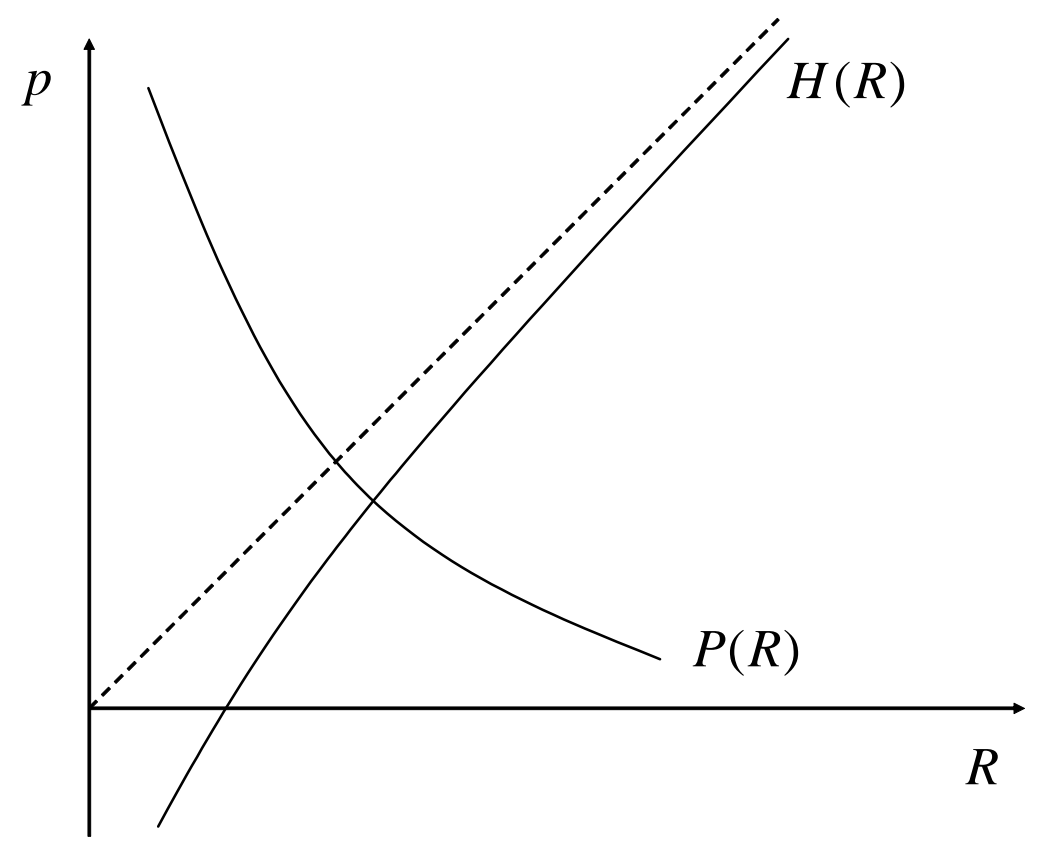

Figure 2

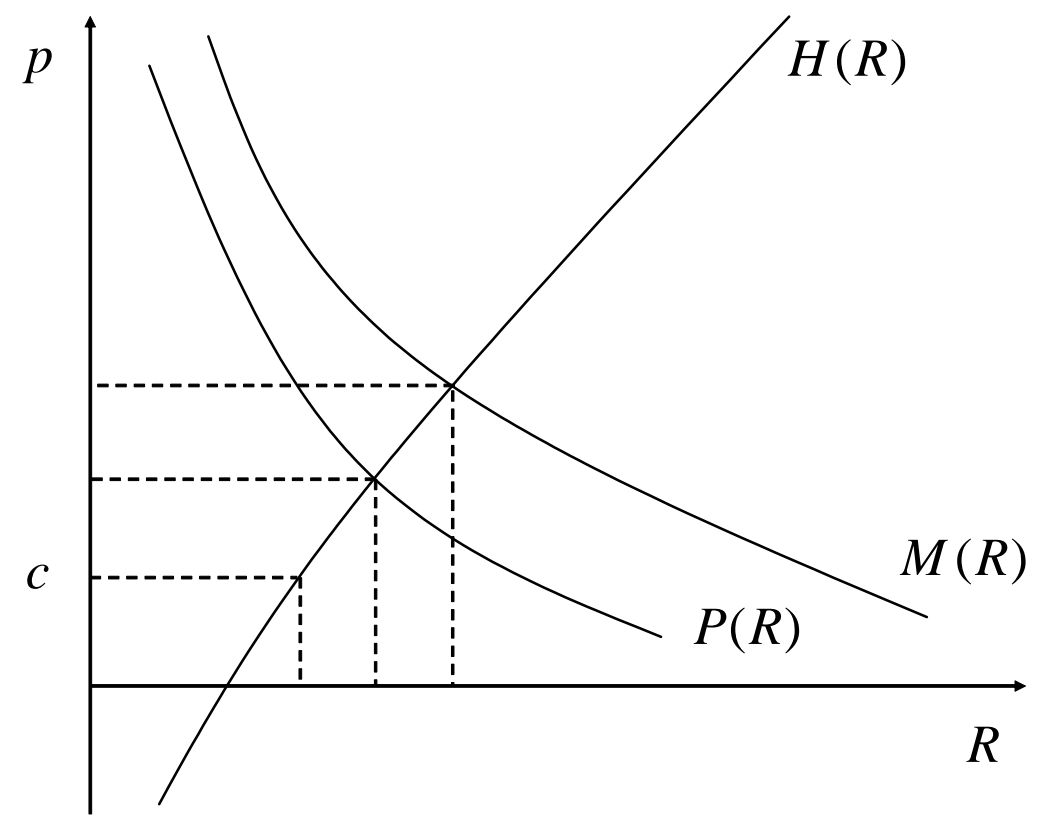

